\title{
Qual a identidade de nosso curso?* (Subsídios para a revisão do Projeto Pedagógico do curso de Filosofia da UCDB)
}

\author{
Otaviano José Pereira
}

Doutor em Filosofia e História da Educação, pela UNICAMP, Professor-visitante da UFMS e docente do programa de Mestrado em Educação da UCDB.

"É necessário que eu me faça com aquilo que fizeram de mim" (Jean-Paul Sartre).

\section{Apresentação}

Às vezes trabalhamos com duas idéias equivocadas: a) a de que "toda educação" é um bem em si mesma; ou, b) a de que "qualquer uma" é melhor que nenhuma. E isto pode nos levar a um comodismo que não nos permite um questionamento ou no mínimo uma avaliação de nossa ação como educadores. E então perdemos o sentido de ser trabalhadores em educação, comprometidos com ela e suas circunstâncias, caindo na esterilidade dos "tarefeiros" da escola.

Neste momento da UCDB, aliás privilegiado, de transformação em universida- de, (privilégio para quem? - alguém poderia indagar com muita pertinência), é hora, antes de mais nada, de revelar, à luz do dia, nossa vocação universitária. E para que tal manifestação (tal "epifania") aconteça, creio que necessitamos de um engajamento pessoal de cada membro dos corpos docente e discente e da direção, de modo que todos se disponham a entrar num processo de reflexão, avaliação, estudo e decisão em cima de um Projeto Pedagógico à altura de nossa vocação de grandeza. E, nada mal, se entendemos a Filosofia como espaço onde o fogo sagrado da indagação sempre se reacende, seja qual for a circunstância; aliás, precisamente devido às

\footnotetext{
* Texto apresentado num trabalho de assessoria pedagógica pelo professor Otaviano Pereira aos docentes e discentes do curso de Filosofia da UCDB, em setembro de 1993, como ponto de partida de um empenho conjunto no sentido de renovação do Projeto Pedagógico do curso. As discussōes culminaram com uma reestruturação nos limites do possível da grade curricular e uma dupla proposta: da continuidade do processo de discussão em 1994, e de montagem de um "lato sensu" em Filosofia com uma preocupação interdisciplinar (aberto à comunidade universitária) e como substitutivo paralelo e opcional do suposto $4^{\circ}$ ano do curso regular.
} 
circunstâncias, nem sempre favoráveis.

Não acredito em soluçōes prontas; nem de cima para baixo e nem de "salvadores da pátria" que nos dêem os "seus" caminhos de reflexão e de norteio para nosso curso. Acredito no potencial humano que temos e que, desprendidos de posições unilaterais e amadurecendo nossa consciência coletiva à luz da participação comunitária, possamos promover mudanças que se fazem necessárias em nós e nas estruturas com as quais costumamos a viver até por força do costume, da rotinização desta fragmentada pós-modernidade.

Neste sentido apresento para nós todos hoje um texto que será nada mais que o ponto de partida de uma reflexão; não pretende ser algo acabado, a última palavra. Pretende, isto sim, nos apontar pistas para um início de trabalho e uma metodologia que poderá ou não ser escolhida e aplicada.

Assim postas as coisas, convido todos a um conjunto de reuniōes e debates após uma leitura individual mais cuidada: a um seminário aberto onde traçaremos as linhas gerais de um trabalho. Se tudo correr bem, como pressupomos, deverá culminar num texto-magno, base do novo Projeto Pedagógico do curso de Filosofia da UCDB - quem sabe, inspiração futura para outros cursos? - a ser executado a partir de 1994.

Desde já conto com o empenho e a participação de cada um!

\section{Introdução}

Ao nascer uma criança, é notório via de regra que as famílias tendem a "disputála" pela aparência: é a cara da mãe, do pai, do tio, etc. Ter os olhos azuis ou castanhos, o cabelo liso ou crespo... são indicadores de uma filiação, parentesco, linhagem... enfim, uma identidade. E às vezes a cara é tão evidente que não precisa "disputas".

Seria salutar que tal coisa acontecesse com nosso curso. Vale dizer, não só que tivesse seu "rosto próprio" - o que é muito provável - mas que se desse a conhecer. As intempéries do obscuro tempo histórico em que, via de regra, nasceram nossos cursos podem ter levado nosso rosto à intimidação, ao "esconderijo do capuz".

É por isso que neste momento estamos convidando a todos, alunos, professores a nos ajudar a "redescobrir nossa cara". Urge elaborarmos um projeto pedagógico próprio, atualizado. Quem sabe, desengavetar idéias e práticas que darão um tom agora mais afinado ao mesmo.

Entendemos que a elaboração (ou reelaboração) de um projeto pedagógico para o curso de Filosofia da UCDB, só logrará êxitos se não for idéia ou iniciativa de uns poucos, mas se perpassar uma dinâmica de discussão vertical e horizontal que envolva todos os sujeitos deste processo. Além do mais, acreditamos que a idéia e execução de um projeto pedagógico que nos leve a redescobrir nosso rosto deve ser arquitetado na alegria do labor cotidiano e em consideração a um processo histórico em andamento e não ao modo de uma ação de carpideiras: "isto serve, isto 
não serve...". Entendemos, ainda, que os professores da UCDB representam uma mão de obra dedicada e eficiente à medida de suas forças e possibilidades, virtudes e limitações, de forma que, nós mais que ninguém conhecemos as rugas e os contornos desse rosto que ora ousamos redescobrir. Daí o fato de que estes apontamentos vêm tão somente somar-se aos esforços de anos de labor, lutas e alegrias de todos os que vêm cinzelando, esperançosamente, o artesanato desse rosto, que está na hora de aparecer sem medo. Para tanto, temos em mira algumas atençōes aqui postas como pressupostos pedagógicos. Se não, vejamos.

\section{Atenção para com os contextos histórico e geográfico}

A sociedade brasileira, como sociedade dependente econômica, social e culturalmente, carrega nas costas o fardo de uma política sócio-econômica ditada "de cima para baixo" (do Norte para o Sul), pelos centros econômicos que costuram a hegemonia do capital monopolista e produzem o colapso financeiro, mesmo sob a ideologia dissimuladora e narcísica do paraíso artificial de pós-modernidade. O resultado disso é o consumismo desenfreado (inclusive sobre a cabeça de uma juventude que tira e perde a vida no portão da uma escola por causa de um simples par de tênis da moda!), o nomadismo: êxodo rural e inchaço das grandes cidades, a dramaticidade dos sem-terra e sem-teto, etc... Enfim, acabou a ditadura política; do autoritarismo tecnocrático onde o fio da navalha da linguagem econômica vai aparando todas as nossas arestas no cotidiano (impostos sobre impostos, o pior nível salarial de todos os tempos com percentuais gastos em "fundos perdidos", como o ex-INPS que a nada mais serve, etc.). E um povo com nenhum problema básico resolvido ainda se vê obrigado a ingerir a ideologia neo-liberal na cantilena da modernização de um governo dependente, (este sim, sem uma "cara-própria", que tudo tenta justificar na mistificação da liberdade de mercado para poder privatizar o que ainda resta do patrimônio nacional inclusive educação e saúde).

Do ponto de vista da geografia do MS, Campo Grande não parece ser uma ilha de tranqüilidade no mar revolto de uma sociedade brasileira com uma economia tão estrangulada. E, muito menos, de um sistema educacional sucateado nas últimas décadas.

Se a universidade brasileira tornouse, nos últimos anos e por várias razōes, a reprodutora das contradiçōes da sociedade e com um modelo que aprofunda cada vez mais a tarefa discriminadora de um ensino elitista e ineficiente, cumpre saber se, entre nós, ao redescobrir nosso rosto, temos condiçōes de abrir espaços para repensar estas contradições e criar o novo. O novo efetivo, não como modismo (de métodos, por exemplo), mas como a vanguarda de uma ação educacional de fato libertadora (que leve em consideração os projetos populares, a efetiva universalização das oportunidades, por exemplo).

E aí algumas questões, imperativas, nos assaltam a consciência: 
Será que o nosso papel é apenas e tão somente o de formar mão de obra para o capital com um ensino aviltante (de baixo nível, etc.) transformando em mercadoria barata a ser vendido na bacia das almas do mercado de uma sociedade dependente? Ou será que nosso papel tem sido o de fornecer uma mão de obra pelo menos um pouco mais "qualificada" com um mínimo de nível de pesquisa, mas subordinado apenas aos interesses das classes dirigentes e não voltado para as reais necessidades das comunidades circundantes e seus projetos de crescimento? Ou, um ensino com pesquisa e extensão mas sem um mínimo de senso crítico e apenas voltado às necessidades imediatistas de um sistema (nacional e estadual) de educação, sem nenhum projeto de fato transformador da sociedade como um todo, (a partir dos "de baixo" - Florestan Fernandes), tendo em vista a geografia local? Ou, finalmente, um ensino que apenas dá continuidade a uma herança histórica recebida e, como a biruta de um aeroporto, vira para onde o vento empurra, sendo direcionado apenas de fora para dentro?

Estas e outras são questōes que merecem nossas consideraçōes num projeto pedagógico, sob este item.

\section{Atenção para com o envolvi- mento dos sujeitos da ação educadora}

Todos nós, do diretor ao varredor, estamos inseridos no contexto da UCDB não como moradores de um prédio de apartamentos em que só nos vemos nos eleva- dores ou em sonolentas reuniōes de condomínio. O processo de envolvimento dos sujeitos da ação educadora é mais profundo. Se estamos construindo conjuntamente uma ação educadora, então os espaços devem ser todos ocupados.

Do ponto de vista docente, a possibilidade de criação de uma associação, não só para reivindicar salários, mas para amadurecer a convivência em torno de objetivos comuns, conquistar contratos de trabaIho que fixem o docente na universidade, preparando aulas, orientando alunos, se reciclando, criando textos, tendo tempo para colaborar em jornais e revistas, criar projetos, apontar alternativas, usufruir da alteridade das relaçōes, etc.

Uma mão de obra volante que só transita os caminhos entre as salas de aula e sala dos professores, de vez em quando a biblioteca e, no final do ano, o salão de formaturas... como pode crescer e ajudar o aluno a crescer? Como pode amadurecer a convivência em torno de objetivos comuns?

Do ponto de vista discente, o aluno precisa começar a sentir a faculdade como o seu espaço de convivência e de amadurecimento. Como irá mais tarde "sentir saudades" de uma faculdade onde não deixou lastros, não criou raízes, não ampliou sua visāo de mundo?

Do ponto de vista dos funcionários, também a abertura de frentes de organização, tendo em vista seus direitos, bem como uma relação mais estreita com o processo pedagógico, de tal maneira que também se sintam, em certa medida "educadoreseducandos" e não só prestadores de serviços. Em outras palavras, não só questão 
do bom atendimento, mas do envolvimento de corpo e alma no processo pedagógico como um todo. (Por exemplo, bibliotecárias formadas para orientar pesquisadores, não só para retirar livros).

\section{Atenção para com a unidade (e não só uniformidade) da ação}

O conjunto de ação sem pluralismo gera a pluralidade da ação estereotipada e está a um passo da desintegração. É a uniformidade. O conjunto de ação plural, no convívio das diferenças, conduz à integração "ad intra". É a unidade. Às vezes confundimos unidade de ação apenas sobre a fachada da uniformidade. Daí, a "militarização" de certos modelos ou processos de ação, que se esvaziam em seus objetivos explícitos: regras, estereótipos. Num processo pedagógico em que os sujeitos envolvidos, neste caso os educadores-educandos e educandos-educadores dão a tônica do "discurso de sentido" de sua operacionalidade, o que conta para valer é o conjunto de ação plural, advindo de um consenso que não tem sua razão de ser nas formas como fim, mas como meios. Aí o processo didático-pedagógico pode (e deve) ser rico, pluriforme. Por exemplo, o caso das chamadas em classe. Se deslocadas do "meio" para se tornarem "fim em si mesmas", algo deve ser repensado aí (autoritarismo? forma de pressão?). Ora, se por um lado um professor entende que esta é uma maneira de celebrar um acordo de trabalho com os alunos e todos enxergam o sentido e o motivo da chamada, tudo bem. Se, para outro, a chamada tornou-se uma forma esclerosada e vazia de "cobrança”, também esta maneira de encará-la deve ter uma transparência de "jogo posto" aos alunos. O que não podemos é afirmar em alto e bom tom que a Filosofia da UCDB tem um projeto pedagógico (fundado na uniformidade e "militarizado") porque aqui todos os professores "fazem chamada em aula", assinam ponto e, portanto, são "sérios" e "responsáveis". O resultado de seu trabalho deixa de ser visto no conjunto e cede às minúcias.

A atenção com a unidade da ação tem também um alcance estrutural mais abrangente e, por conseguinte, um alcance "político". Uma ação educacional sem um projeto pedagógico para valer, que não leva à integração pelos seus fins e com objetivos democraticamente resolvidos a partir do convívio com as diferenças, pode conduzir à formação de "igrejinhas" que nada contribuem para uma educação, então carente de um projeto conseqüente e muito menos para o crescimento dos sujeitos envolvidos. Os objetivos fracassam fatalmente quando entram em cena jogos de influência e disputas de poder que obscurecem, dissimulando-os em intrigas e mesmices que até soam como "formas de luta", de modo que tudo se resolve "no chopinho da mesa de bar", diz-que-diz de corredores, etc. O compromisso político aponta para a competência técnica e vice-versa. A competência técnica pōe as regras para o compromisso político e ambos se dão num estado permanente de provisoriedade pela necessidade de renovação e não de mascaramento. É isto que nos permite reinventar sempre a escola (e universidade) com o aspecto de ser me- 
diadora e não reprodutora pura e simples das relaçōes que a circundam. "A escola não pode concorrer para mascarar ou criar tampões nos olhos dos educandos. Não pode fazer o jogo de esconder a realidade porque ela não é arma para produzir felicidades ou infelicidades, mas mediação entre a realidade empírica e o seu conhecimento. A escola pode ser o bisturi que abre os olhos para a compreensão do mundo" (RODRIGUES, Neidson, Da mistificação da escola à escola necessária, p. 64).

\section{Atenção para com uma ética de libertação integral dos sujeitos envolvidos}

Uma educação universitária, seja em que patamar ela se estabeleça - ensino de Ciências humanas, exatas ou biológicas e principalmente a Filosofia - deve ter em mira a formação humana plena e a compreensão da totalidade do real: o real humano, seu lado antropológico, e o real social, a consideração do educando como um ser de relaçōes, consigo mesmo, com o outro e a sociedade (as classes sociais) e a natureza. "A educação humaniza e personaliza o homem, quando consegue desenvolver plenamente o seu pensamento e liberdade, fazendo-o frutificar em hábitos de compreensão e comunhão com a totalidade da ordem real, hábitos: com que o homem humaniza seu mundo, produz cultura, transforma a sociedade e constrói a história" (Conclusōes de Puebla, 829, apud Projeto pedagógico do Instituto de Filosofia da PUCCAMP, p. 21).

$A$ atenção para uma ética de liberta- ção integral dos sujeitos da educação deve ter em mira o sujeito situado em seu contexto como o "de onde", o lugar "tópico" concreto de uma ação pedagógica libertadora, porque leva em consideração sua identidade, seu contexto sócio-histórico e cultural, bem como as contradiçōes que os sujeitos (educadores-educandos e educandos-educadores) devem superar.

Do ponto de vista da elaboração de conteúdos curriculares não se trata de postar em atitudes antropofágicas e ficar ingerindo o receituário teórico vindo de fora para dentro, mas saber fazer o descascamento crítico do saboroso fruto das idéias sem, por outro lado, cair na xenofobia inoperante. Mas um projeto pedagógico sério nos leva a uma atitude de distanciamento crítico necessário para melhor assimilarmos as idéias dos "outros", na relação de alteridade com o "diferente" de nós, mas sempre bem vindas, embora muitas vezes sob o impacto emocional dos modismos (e cada década tem tido os seus).

A atenção para com uma ética de libertação integral dos sujeitos também deve apontar para uma postura lúcida de superação de alguns impasses na área pedagógica que nos cumpre saber.

a) Saber que uma teoria da educação brasileira vazada num processo pedagógico para esta ou aquela circunstância histórica e geográfica, tem de superar o estágio do mero impacto de novos métodos, como se reinventar métodos a bel prazer fosse recriar a educação. Por exemplo, didatismo bem ao estilo das doutrinas "psicologistas" voltadas para o "conhecimento da clientela" e nada mais. Educação não é livro de 
receitas de Dona Benta e nem deve se curvar a tantos cantos de sereia dos anos 90 , essa era de cultura tão fragmentária, pragmática e prestadora de serviços.

b) Saber que não basta uma atitude liberalizante (ou liberal no sentido clássico do "reino da igualdade"), quando a relação tradicional professor-aluno, que há muito já caiu num esvaziamento de funçōes, ao invés de ser sadiamente problemática, acaba escondendo o discurso social real. Vale dizer, a desigualdade social dissimulada na "igualdade" de relaçōes. Não assumindo que a escola também é um dos espaços da desigualdade, o professor passa a ser idolatrado porque "se rebaixa ao nível da clientela". Nas décadas de 60/70 essa relação de poder real se diluía nas técnicas de sociodrama, dinâmica de grupo, etc., numa espécie de "democracia sem povo", visando a resolver não as questōes educacionais básicas, mas o esvaziamento das próprias relaçōes de poder em que a escola, via de regra, é uma reprodução mesmo dissimilada.

c) Saber que não se trata de uma atitude sofista (no sentido depreciativo do termo) em que o educando-educador (aluno) é levado a reconhecer seu valor de forma artificial a partir de um discurso pedagógico individualista, pseudo-valorativo e aliciador. Este discurso "ético" (nas aparências) não interfere nas relaçōes mais amplas que a educação implica e sequer consegue estabelecer uma crítica ao ensino "bancário e competitivo" (P. Freire). Num espectro humanitário, portanto pseudo-humanista, confunde a formação humana integral com o subjetivismo doutrinário do tipo: "educar para a vida", etc. d) Saber que a luta de classes não acontece fora e nem independente da educação, e que um dos sujeitos de relaçōes, no caso o educando-educador, nossa grande preocupação, só age dentro dos parâmetros da luta de classes. Esta é uma opção básica de "leitura" circunstancial e integral do educando para se propor uma ética pedagógica para valer: não "humanitária", informativa, puramente conteudística... - Ora, é sabido que não se aprende Filosofia (conteúdo) se não se aprende filosofar (atitude apoética, enfrentamento ao real). E aqui seguimos os rastros do pensamento do filósofo da libertação latino-americana Enrique Dussel - no sentido mesmo de uma tomada de opção: ou definimos se a educação em que está inserido o educando está ou não ligada à luta de classes ou não. Se não estiver (ou: se não tivermos consciência disso) não interessa quaisquer métodos de ensino, por mais "revolucionários": psicologistas, sociologistas, liberalistas, democráticos... É tudo engodo, embuste, às vezes sob as peias do próprio senso comum que nos leva a consumir modismos teóricos como consumimos sandálias da moda e ainda afirmar cinicamente que estamos fazendo "ciência neutra".

\section{Atenção par a com uma pedago- gia transformadora e abrangente}

Um projeto pedagógico conseqüente tem de levar em conta que nenhuma teoria da educação pode ter como ponto de partida algo fora da educação. Mas nenhuma teoria da educação pode se afirmar sem ter, fora da educação, os elemen- 
tos que a explicam. Esta é a base de toda crítica da prática pedagógica.

Assim postas as coisas, sem ficarmos numa postura de apenas ver a escola, e nela a universidade e na universidade nosso curso como meros reprodutores das relações sociais de produção, cremos que precisamos reivindicar um projeto a partir de uma postura pedagógica transformadora e abrangente. Para tanto, cumpre que nossa ação educadora seja crítica, progressista, prazerosa e alegre, dialógica, conflitiva (ou problematizadora), de conteúdos e, finalmente, política.

Esta ação, e toda teoria que a "ilumina", não deve esvaziar-se na crítica dos métodos (apenas) mas assumir o político sem medo. Não é "pecado" reconhecer na função do educador e do educando uma função política. No mínimo nos referimos ao sentido aristotélico do "homem, ser da polis". É aí que se encontra sua especificidade. Se o educador já descobriu esta especificidade de sua função tanto melhor; se não, ponha num museu. Pois é nesta especificidade que ele se define como agente transformador não no sentido reacionário de "formador de cabeças" e muito menos "ação política" no sentido de trabalhar para candidatos em anos eleitorais"... O "ethos" político da ação pedagógica é algo muito mais nobre que esta compreensão tão estreita da palavra. (Ainda que a política enquanto exercício "maquiavélico" do poder tente a todo momento estreitar os espaços da ética em favor do "realismo" de seu exercício). Na verdade, quando falamos em educadores às vezes o tratamos de modo meio difuso. De fato todos somos educadores, "inclusive" os professores, que são educadores-educando, ou pelo menos devem se descobrir como tal. Mas não são povo, nem sistema e muito menos inocentes úteis - que carregam sozinhos o sistema nas costas. O Educador-educando (professor) é um agente orgânico que atua dentro do conflito de classes como os outros. E um projeto pedagógico que não enfatiza isto, ou pelo menos o percebe implicitamente, não enxerga o lugar da educação na sociedade, perde sua especificidade política e, daí, o próprio direito de reivindicar o lugar da educação na hegemonia cultural. (Por exemplo, jamais conseguirá incorporar nela a luta popular para poder ser menos elitista, etc.). Um projeto pedagógico que não pressupōe isto, como "a priori", vai transformar o quê?

\section{Atenção para com a natureza, especificidade e finalidade do curso}

Se queremos formar "filósofos", o que esta missão espinhosa significa? Todo filósofo está diante de seu tempo, como Sócrates e os sofistas, impotentes, dando braçadas de diálogos frente ao mar revolto de idéias desfavoráveis.

De nada adianta um projeto discutido que serve ao curso burocraticamente; pois este curso não serve ao nosso tempo porque não o muda; é sobre nosso tempo que nosso projeto se assenta e se renova. A resposta ao nosso tempo é a prova de fogo de concreticidade de nosso projeto. 
Mas se trata de uma estrada em mão dupla. O curso ganha rosto, identidade, no marco de um projeto pedagógico com as preocupaçōes que aqui salientamos e outras que advirão no processo de discussão geral, por áreas, conteúdo, matéria, currículo, etc. Vale dizer, um projeto não deve ser um "a priori" puro e simples. É um "jogo posto" dos sujeitos envolvidos e em aberto, sabendo que renovação não se faz por decreto. Jogo posto, em aberto, em cima de questōes fundamentais e não de questiúnculas. Por exemplo: qual especificidade de um curso de Filosofia? Um curso que simplesmente reivindica ser o "locus" da reprodução da razão universal e abstrata, ainda que rigorosamente postulado? Cumpre lembrar que todo acúmulo de erudição por erudição acaba servindo para "esconder" a formulação do pensamento. O erudito "sabe" o que lê; o filósofo arranca o saber da atitude, inclusive frente ao acúmulo de leituras. Um curso que, por outro lado, perde sua especificidade na absurda fragmentação do conhecimento ora em voga? Um curso que não pōe em crise, em aporia, a emergência do pensar como instância fundamental do homem situado? Um curso que simplesmente repete o receituário de compêndios e presta um desserviço idolátrico às "escolas" e aos "sistemas", sem encontrar o espaço de sua respiração própria, sua autonomia? Um curso que não reconhece o lugar da filosofia frente às demais ciências, ao cientificismo e à tecnocracia, mesmo sob a pecha de "inutilidade"?

\section{Atenção para com o ensino, a pes- quisa e a extensão, conjuntamente}

Esta questão é problemática e deve estar no centro de nossas preocupaçōes. Primeiramente porque educação não é pesquisa sem deixar de ser educação. Aqui há problemas de fronteiras que estão permanentemente reclamando soluçōes e as epistemologias o revelam.

Em caráter provisório estamos lembrando aqui da pesquisa em seu sentido mais abrangente, "in lato sensu". Trata-se de uma questão de divisor de águas ou de afluentes que mexe com a prática do conhecimento organizado. Se, num exemplo bem prosaico, a Fundação Johnson \& Johnson faz pesquisa de qualidade em seus laboratórios melhor que muitas universidades brasileiras, deve continuar a fazê-lo. A questão está é na relação que se estabelece entre uma multinacional e a sociedade; isto é, à primeira vista não é problema específico da educação - a não ser em eventuais convênios, etc. trocando em miúdos: pesquisa, no sentido laboratorial e não só "acadêmica" não é privilégio de universidades (que aliás surgiram no século XIII antes das experiências de laboratório) embora seja ideal que as universidades o façam. E faça-o bem feito! Pois a sua especificidade é ser o espaço privilegiado do ensino, da pesquisa (laboratorial e acadêmica) e de extensão, no mínimo.

Tudo bem. Mas há um nível de pesquisa advindo da relação ensino-aprendizagem, em que a escola (ou universidade) se torna, toda ela, o espaço privilegiado, pelo menos do ponto de vista de sua iniciação. 
Aí os educandos devem ser devidamente instrumentalizados, no sentido prático e no sentido teórico. No sentido teórico, a partir da consciência da própria dimensão e natureza da pesquisa (por exemplo, ao discutir o tão debatido "mito da neutralidade"); seu lugar, bem como a conquista do espaço disciplinar às demais ciências e a quebra de presumíveis prioridades questionáveis, dadas às ciências exatas e biológicas sobre as ciências humanas ou vice-versa fato que já se revela "ideológico"; o conhecimento da pesquisa no seu arcabouço histórico (por exemplo, saber matemática como "história da matemática", etc.); a instrumentalização técnica: laboratório, bibliotecas e recursos lógico-metodológicos: considerações em torno do ato da leitura, da assimilação de idéias, a devida instrumentalização conceitual, bem como o processo do conhecimento em sua especificidade (exemplo, saber que estudar um texto filosófico não é o mesmo que estudar história ou ler poemas, etc.) seus alcances, inclusive emocionais e afetivos, intuitivos e artísticos; estrutura e apresentação de trabalhos escritos dentro das categorias e normas metodológicas próprias da ciência em questão, com embasamento de ordem crítica, lógica, metodológica e epistemológica.

\section{Atenção para com o I e II graus}

Uma das grandes lacunas da Universidade brasileira, além de seu distanciamento com a sociedade em geral, é a falta de elo e sintonia com o l e ll graus. É como na famosa imagem das duas montanhas muito próximas mas separadas por um profundo abismo. (Esse abismo seria a representado pelo vestibular?)

É um erro pensar que a aproximação se resolve só na fria interação das disciplinas em seus conteúdos, programas, ementas. Esta aproximação também é necessária, mas não basta por si só; é mecânica e não pedagógica. A questão vital é da aproximação umbilical de projetos. Projetos que considerem o educando-educador (aluno), seu perfil, seus anseios, suas utopias, sua inserção na realidade, na sociedade de classes, na cultura... bem como (que considerem) o educador-educando (professor), sua luta, seus desafios, os objetivos comuns de sua operacionalidade educativa, a convivência sadia entre as duas instâncias da escolaridade, a troca de experiência profissional, etc.

É salutar que se estabeleçam fóruns de debates envolvendo docentes e discentes do I e II Graus e universidade para discutirem as metas e desafios comuns. Espécie de semana integrada de estudos em que todos são chamados à participação nessa discussão dos objetivos comuns.

\section{Atenção para com a qualidade}

Do que dissemos até agora a qualidade pode ser encarada como o corolário de um projeto, uma vez que este passa a ser posto em prática e criteriosamente discutido, avaliado. Uma preocupação que se estende desde o cuidado com a reciclagem dos professores, o plano de carreira, a aquisição ou renovação de equipamentos de apoio didático, e tantos outros.

Do ponto de vista do ensino cumpre 
não deixarmos cair na cantilena do atendimento às necessidades do "sistema educacional" que está aí e nivelarmos nosso curso a partir "de baixo". Isto já significaria agir em desfavor da qualidade. Só a crítica bem fundamentada do modelo de ensino vigente repõe a qualidade em circulação, ainda bem que problematicamente. Não no sentido meramente empresarial e técnico de qualidade que se quer hoje reivindicar à educação como forma de imprimir eficiência à adaptação à relação capital e trabaIho que por hora passa por uma profunda alteração estrutural - informatização, terceirização, desemprego em massa, etc.

É evidente que a tão propagada questão da qualidade pode parecer meio "farisaica" se não colocarmos os pés no chão e respondermos a questões imperativas como: quem educa o educador? e outras. A universidade como um todo deve responder por esta questão em primeiro plano, e a filosofia lançar seu olhar crítico, radical e de conjunto sobre tal questão.

\section{Atenção para com a desburo- cratização das relações}

Entendemos burocracia aqui no aspecto puramente negativo. Com a lei 5.504 da Reforma de 68, a departamentização e outras que se seguiram (inclusive o Decreto chamado Rubem Ludwuig, n. 85.487/80, entre tantas outras excressências do regime de exceção), a universidade teve seus espaços internos ocupados por profissionais do regime lotados nos departamentos e que nada faziam que levar e trazer papéis, como a forma consentida de transacionar o poder, traficar influências, etc. É necessário envidar esforços, "desviciar" as relaçōes, para que os educadores comprometidos com tal projeto se atenham às necessidades básicas da educação de modo a desintoxicar de vez as heranças daqueles tempos.

\section{Atenção para com o corpo}

Muitos cursos de filosofia servem para formar "bibliotecas ambulantes". A erudição não é um mal: longe de pensar tal disparate. Pelo contrário, é decorrência de trabalho sério. Entrar na "causa primeira" do pensar significa em certa medida ter que "queimar pestanas", ter disciplina intelectual, etc. O mal é ter a cabeça desproporcional ao corpo. E não falamos em corpo aqui no sentido da corpolatria pós-moderna, da malhação do prazer gratuito. Falamos em corpo aqui no sentido psicanalítico mesmo: no sentido de que responde "para si" questões que a razão "em si mesma" não responde, e concretiza as utopias positivas o corpo da saúde, do prazer, do esporte... bem como do sentido fenomenológico da corporeidade.

\section{Sugestões de operacionalidade}

A elaboração de um Projeto Pedagógico da Filosofia, descoberta ou redescoberta de sua identidade, deve caminhar não só sobre os trilhos da discussāo teórica, que repassa o projeto, como propor metas de ação comum. Para tanto, sugerimos os seguintes passos:

a) Formação de uma equipe peda- 
gógica para preparar seminários para que o projeto seja elaborado e discutido em seu conteúdo, sua amplitude, seus detalhes e sua aplicabilidade.

b) Formação de equipes de trabalho para discussão, sobre o perfil do curso: sua natureza, sua especificidade, a grade curricular, o conteúdo e/ou teor de cada disciplina, a abertura de "frentes" (novas disciplinas com propostas inovadoras de ensino e pesquisa), o levantamento das necessidades mais prementes mas com uma visão clara dos objetivos a serem alcançados, bem como da dimensão da ação educacional na área.

c) Seminários democraticamente instalados para discussão de intrincados problemas que perpassam o curso, como por exemplo o da avaliação (aprendizagem, auto-avaliação, etc.) como um processo contínuo, aberto, crítico e não "bancário".

d) Discussão, em seminários, de métodos e critérios de avaliação de professores e avaliação desses critérios com assessoria pedagógica, dentro do perfil do curso.

e) Discussão envolvendo docentes, discentes e um assessor da área, sobre a tríplice questão: recuperação, adaptação e dependência, dentro de uma atitude dialó- gica e que ao mesmo tempo não signifique "afrouxamento", "complacência", etc.

f) Discussão, entre os docentes, sobre a possibilidade ou impossibilidade de uma ação unitária das disciplinas e uniforme no sentido de propor avaliações conjuntas, pelo menos nas matérias que mais se aproximam. Por exemplo, o educando escrever um texto sobre o conteúdo da matéria $X$, sendo orientado também pelo professor de gramática, de metodologia científica, assim por diante.

g) Discussão, em longo prazo, envolvendo docentes e discentes, de propostas de monitorias para alunos como formas de amadurecimento de suas próprias caminhadas nos referidos cursos.

h) Discussão sobre a viabilidade ou não do aluno (ou grupo de alunos) apresentar um trabalho monográfico - síntese do curso como pré-requisito para conclui-lo.

i) Discussão de um plano de carreira que possibilite ao professor dedicar-se de forma mais integral à ação educadora e em prol da qualidade de seu trabalho.

j) Redação conjunta do texto do Projeto e, se possível, publicação do mesmo Bem, a discussão está posta, mãos à obra. 